\title{
Unangan Past and Present: The Contrasts between Observed and Inferred Histories
}

Author(s): D. H. O'Rourke, D. L. West, and M. H. Crawford

Source: Human Biology, 82(5/6):759-764.

Published By: Wayne State University Press

URL: http://www.bioone.org/doi/full/10.3378/027.082.0515

BioOne (www.bioone.org) is a nonprofit, online aggregation of core research in the biological, ecological, and environmental sciences. BioOne provides a sustainable online platform for over 170 journals and books published by nonprofit societies, associations, museums, institutions, and presses.

Your use of this PDF, the BioOne Web site, and all posted and associated content indicates your acceptance of BioOne's Terms of Use, available at www.bioone.org/ page/terms_of_use.

Usage of BioOne content is strictly limited to personal, educational, and noncommercial use. Commercial inquiries or rights and permissions requests should be directed to the individual publisher as copyright holder. 


\title{
Unangan Past and Present: The Contrasts Between Observed and Inferred Histories
}

\author{
D. H. O'ROURKE, ${ }^{1}$ D. L. WEST, ${ }^{2}$ AND M. H. CRAWFORD ${ }^{3}$
}

\begin{abstract}
Academic research focusing on the population and culture history of the Aleut (Unangan) people began in the late 19th century and continues to the present. The papers in this special issue of Human Biology summarize the latest results from archaeological, linguistic, genetic, and morphometric research approaches that bear on our current understanding of Unangan history and prehistory. Although these new analyses have provided a level of description and resolution previously unattainable, explanatory models and mechanisms for the patterned variation observed over time in the biological and cultural record of the Aleutian region remains elusive. Bringing the diverse data sets into concordance to represent an integrated synthesis of Aleut population and culture history and of Unangan origins and their relationships with other groups in the region remains a goal for future investigators.
\end{abstract}

The collection of papers is this special issue of Human Biology is intended to synthesize the state of knowledge regarding the origin and dispersal of human populations throughout the Aleutian archipelago. Previous research documented the presence of people in the eastern portion of the island chain for at least 9,000 years, and for a third of that time in the western islands (Near Islands). Thus it has been relatively well established that the Aleutians were colonized from the east, from the Alaska Peninsula, fairly early in prehistory. What has been less easily established are the number of westward colonizing migrations and how the dynamics of local populations gave rise to the observed pattern of biological, cultural, and linguistic diversity that characterizes the modern Unangan (Aleut) population.

One of the strengths, and an original contribution, of this collection of papers is how the contributors to this special issue build on the heterogeneous research of early workers (e.g., Dall 1877, 1899; Hrdlička 1945; Jochelson 1925, 1933; Laughlin 1951, 1967, 1980; Veltre and Smith, this issue) to provide a modern view of Unangan diversity and history through their research in archaeology,

\footnotetext{
${ }^{1}$ Department of Anthropology, University of Utah, Salt Lake City, UT 84112.

${ }^{2}$ Biodiversity Institute, University of Kansas, Lawrence, KS 66045.

${ }^{3}$ Department of Anthropology, University of Kansas, Lawrence, KS 66045.
}

Human Biology, October-December 2010, v. 82, nos. 5-6, pp. 759-764.

Copyright $\odot 2010$ Wayne State University Press, Detroit, Michigan 48201-1309

KEY WORDS: ALEUTS, UNANGAN, ALEUT (UNANGAN) PREHISTORY, ALEUTIAN ARCHIPELAGO. 
genetics, linguistics, demography, culture history, isotopic analysis, and morphometrics. An initial goal of the effort to collect and synthesize results from such disparate analytical traditions was to see whether the different historical reconstructions could be read as concordant. A survey of the results presented here by various researchers indicates some new correspondences across data sets and analytical strategies. It is equally clear, however, that some long-standing questions must await further research using methods with more analytical precision and resolution.

As illustrated by the contributions by Crawford et al. and Rey et al., genetic methods continue to provide a standard of resolution to population history reconstruction that is not often matched by other analytical approaches. Even the historical genetic perspective afforded by ancient DNA analysis (Raff et al.) cannot match the resolution of modern molecular data. The demographic reconstructions from historical records presented by Reedy-Maschner and the use of surname analysis by Graf et al. approach the resolution and precision of genetic analyses, but these studies lack the temporal depth inherent in biological data sets (although Graf et al. contrast surname analysis with Y-chromosome data).

One of the major contributions of this collection of papers is the opportunity to contrast complementary analyses across time slices in the habitation of the Aleutians and adjacent areas. For example, the contrasting inferences obtained from modern (Crawford et al., this issue) versus ancient (Raff et al., this issue; Smith et al. 2009) molecular genetic analyses can be compared to similar contrasts with modern anthropometric variation (Justice et al., this issue) and craniometric diversity of early inhabitants (Ousley and Jones, this issue). In similar fashion, the geographic patterns of variation in biological data across the chain can be compared to the linguistic variation identified across the same geographic area.

In the latter case, the pattern of variation in genes and language appears to be fairly concordant. Crawford et al. identified "zones" of variation that roughly correspond to the three historical dialects of the Unangan language: eastern, central, and western. Of equal interest is Berge's conclusion based on a linguistic analysis of two population movements westward across the archipelago in prehistory. This inference is consistent with both the modern (Crawford et al., this issue) and ancient DNA analyses (Smith et al. 2009) of Aleut populations.

Davis and Knecht address the question of whether Aleut population history as reflected in the archaeological record is the result of local processes and hence is representative of several thousand years of continuity in Aleut populations or whether the record represents evidence for a series of population or cultural influxes. The answer is almost assuredly both, with the archaeological and genetic data, modern and ancient, consistent with at least two population migrations from the peninsula altering local genetic structure prehistorically. This scenario is also consistent with the linguistic synthesis by Berge and is a likely inference from Coltrain's isotopic and radiocarbon analysis of archaeological sites on the peninsula as well. A pan-Aleutian analysis of material culture (Hatfield, this issue) suggests that the earliest Aleutian migrants moved no farther west than the Fox 
Islands, with subsequent movement of peoples or ideas, represented by bifacial technology, the Arctic Small Tool tradition, and ground slate technology, occurring over the following millennia. A surge of ground slate tools and jet artifacts, apparently from the Alaskan mainland circa 1000 BP, across the Aleutians indicates widespread interisland contact relatively late in prehistory with less interaction occurring in the occidental part of the island chain.

But not all results can be read as concordant. Ousley and Jones's craniometric analysis suggests a long period of continuity of even eastern Aleutian populations, providing little evidence of later population incursions and settlement from source populations on the Alaska Peninsula or beyond. Smith et al. (2009), on the other hand, concluded that an observed shift in mtDNA lineage frequencies about 1,000 years ago provided evidence for such a new colonization, and the pilot work of Raff et al. reported in this issue provides some evidence for the source of a later colonization in what appears to be a highly variable and structured population, or populations, inhabiting the Alaska Peninsula in prehistoric times. Such disjunction between morphometric and molecular data in regional population histories is not unusual (e.g., Perez et al. 2009).

In part, such discrepancies may be the result of character sets with different evolutionary histories, easily possible even over fairly short time periods (Jantz and Jantz 2000), especially where they are subject to dramatic differences in environmental sources of variation (but see Justice et al. in this issue). Another issue that is not explicit in these papers but that deserves mention as part of a synthesis is the concept of observed versus inferred migration. This contrast may be one of recent as opposed to deep history. Reedy-Maschner provides a detailed documentation of 19th- and 20th-century migration and settlement in the eastern Aleutians of primarily Scandinavian workers, whose presence ultimately results in the appearance of a dearth of Aleut men. A similar result is reached by Graf et al. in examining surname distributions and Y-chromosome variation. In both of these treatments male migrants, and the paternal lineages they introduce, are overrepresented in subsequent generations, whereas native Aleut maternal lineages, as measured by mtDNA haplogroups, continue to predominate. This asymmetry in admixture at contact or during historic colonization events is not uncommon (e.g., Batista dos Santos et al. 1999; Bosch et al. 2003; Quintana-Murci, et al. 2010). These migration events are "observed" and can be precisely documented with historical sources. In contrast, migrations and colonizations in prehistoric times are not observed but are inferred from genetic and other biological data.

The contrast between observed and inferred migrations, or population influxes, may be critical to how we assess concordance across data sets and analytical approaches. In Reedy-Maschner's demographic history and to a large extent in Graf et al.'s surname and Y-chromosome analysis (both studies in this issue), the modern story of male migration effects and the asymmetric admixture pattern they produce is clear in the Aleutian population context. But the inferred transitions in prehistory derive primarily from aDNA analyses, which rely, to date, exclusively on mitochondrial genetic diversity (Raff et al., this issue; Smith et al. 2009), which is exclusively 


\section{2 / O'ROURKE ET AL.}

maternally inherited. If the aDNA analyses are correct in implying a migrational event as causal in the mtDNA lineage frequency shift observed about 1,000 years ago, then we must posit a different migration scenario from those observed in the historic period. The scenario in the historic period is a primarily male-mediated gene flow event with little impact on the pattern of mtDNA lineage diversity, whereas the earlier event presumes a substantial female contribution to the migration as well; otherwise no observable change in mtDNA lineages would have been detected. And of course, to date, no Y-chromosome data are available for the ancient samples to evaluate the role of males in the inferred migration.

If one goal of the present special issue was to link historic and prehistoric processes that have structured variation in Aleutian populations, the linkage is not yet complete. Although some new insights have emerged and a more synthetic view of Aleut population history is now possible, much work is yet to be done. Certainly, as is almost always the case, additional data would be most helpful. A richer archaeological record of the central Aleutians would fill a major lacuna in our understanding of Aleutian prehistory. Similarly, accessing Y-chromosome as well as autosomal genetic variation in ancient samples would aid in comparing migration models and in contrasting ancient and modern genetic patterns of variation. The quantitative variation assayed by craniometric and anthropometric studies is underlain by genetic diversity in the nuclear genome, and more extensive screens of nuclear genetic data in both modern and ancient samples would be helpful in elucidating similarities and dissimilarities in these data sets. It would also be helpful to have morphometric and genetic information from the same prehistoric samples. The work of Ousley and Jones (this issue) and of Smith et al. (2009) is one of the first such efforts to use modern analytical approaches on both morphometric and genetic data from the same ancient samples-in this case from the skeletal data collected by Hrdlička early in the 20th century.

Hrdlička's (1945) morphological distinction between Paleo-Aleuts and (modern) Aleuts and his replacement hypothesis to account for these craniometric differences have guided much of the research in this region over the past halfcentury (Coltrain et al. 2006). If the hypothesis has merit, the obvious place to effectively test it is in the combined archaeological, morphometric, and genetic analysis of Aleutian populations and of populations inhabiting the Alaska Peninsula during the same time periods. The papers by Raff et al. and Coltrain in this special issue provide enticing views of the peninsula as a collection of differentiated populations that could easily have served as a source for repeated "influxes" to the archipelago. But the populations of the prehistoric peninsula were not uniform in either diet or genetic structure, if these preliminary results are at all indicative. Given the rich archaeological record of the peninsula (Dumond 1981, 2001, 2005; Henn 1978; Maschner 2004; McCartney 1974), integrating the archaeology, genetics, and morphology of prehistoric populations of the Alaska Peninsula is a logical next step in elucidating the history of the region.

In sum, the people of the Aleutian archipelago have a rich, varied, and vibrant past, much like the contemporary population and its future prospects. The 
pathways by which this early dynamism led to the modern Unangan people are finally being drawn more clearly and sharply, as illustrated in the series of papers in this special issue of Human Biology. Future research that focuses on the remaining gaps in our knowledge of Aleut history and population dynamics will provide greater resolution to testing of specific hypotheses.

It is our pleasure to acknowledge our debt to the people of the Aleut communities whose warm welcome, support, encouragement, and participation made possible the studies included in this issue.

Received 27 June 2010; accepted for publication 29 June 2010.

\section{Literature Cited}

Batista dos Santos, S. E., J. D. Rodrigues, A. K. C. Ribeiro-dos-Santos et al. 1999. Differential contribution of indigenous men and women to the formation of an urban population in the Amazon region as revealed by mtDNA and Y-DNA. Am. J. Phys. Anthropol. 109:175-180.

Bosch, E., F. Calafell, Z. H. Rosser et al. 2003. High level of male-biased Scandinavian admixture in Greenlandic Inuit shown by Y-chromosomal analysis. Hum. Genet. 112:353-363.

Coltrain, J. B., M. G. Hayes, and D. H. O'Rourke. 2006. A radiometric evaluation of Hrdlička's Aleutian replacement hypothesis: Population continuity and morphological change. Curr. Anthropol. 47(3):537-548.

Dall, W. H. 1877. On succession in the shell-heaps of the Aleutian Islands. In his Contributions to North American Ethnology, v. 1, pt. 1, Tribes of the Extreme Northwest. Washington, DC: U.S. Government Printing Office, 41-91.

Dall, W. H. 1899. On the Remains of Later Pre-Historic Man, Obtained from Caves in the Catherina Archipelago, Alaska Territory and Especially from the Caves of the Aleutian Islands. Smithsonian Contributions to Knowledge 318. Washington, DC: Smithsonian Institution.

Dumond, D. E. 1981. Archaeology on the Alaska Peninsula: The Naknek Region, 1960-1975. University of Oregon Anthropological Papers 21. Eugene: Museum of Natural and Cultural History, University of Oregon.

Dumond, D. E. 2001. Archaeology in the Aleut Zone of Alaska: Some Recent Research. University of Oregon Anthropological Papers 58. Eugene: Museum of Natural and Cultural History, University of Oregon.

Dumond, D. E. 2005. A Naknek Chronicle: Ten Thousand Years in a Land of Lakes and Rivers and Mountains of Fire. Research/Resources Management Report ARR/CRR-2005-54. King Salmon, AK: Katmai National Park and Preserve, National Park Service.

Henn, W. 1978. Archaeology on the Alaska Peninsula: The Ugashik Drainage, 1973-1975. University of Oregon Anthropological Papers 14. Eugene: Museum of Natural and Cultural History, University of Oregon.

Hrdlička, A. 1945. The Aleutian and Commander Islands and Their Inhabitants. Philadelphia: Wistar Institute of Anatomy and Biology.

Jantz, R. L., and L. M. Jantz. 2000. Secular change in craniofacial morphology. Am. J. Hum. Biol. 12:327-338.

Jochelson, V. I. 1925. Archaeological Investigations in the Aleutian Islands. Carnegie Institute of Washington Publication 367. Washington, DC: Carnegie Institute.

Jochelson, V. I. 1933. History, Ethnology, and Anthropology of the Aleut. Carnegie Institution of Washington Publication 432. Washington, DC: Carnegie Institute. [Reprinted 1968 by Anthropological Publications, Oosterhout, The Netherlands]

Laughlin, W. S. 1951. A new view of the history of the Aleutians. Arctic 4:75-88. 


\section{4 / O'ROURKE ET AL.}

Laughlin, W. S. 1967. Human migration and permanent occupation in the Bering Sea chain. In The Bering Land Bridge, D. M. Hopkins, ed. Stanford, CA: Stanford University Press, 409-450.

Laughlin, W. S. 1980. Aleuts: Survivors of the Bering Land Bridge. New York: Holt, Rinehart \& Winston.

Maschner, H. D. G. 2004. Traditions past and present: Allen McCartney and the Izembek Phase of the Western Aleutian Peninsula. Arctic Anthropol. 41(2):98-111.

McCartney, A. P. 1974. Prehistoric cultural integration along the Alaska Peninsula. Anthropol. Pap. Univ. Alaska 16(1):59-64.

Perez, S. I., V. Bernal, P. N. Gonzalez et al. 2009. Discrepancy between cranial and DNA data of early Americans: Implications for American peopling. PLoS One 4(5):e5746; doi:10.1371/journal. pone.0005746.

Quintana-Murci, L., C. Harmant, H. Quach et al. 2010. Strong maternal Khoisan contribution to the South African Coloured population: A case of gender-biased admixture. Am. J. Hum. Genet. 86:611-620.

Smith, S., M. G. Hayes, G. Cabana et al. 2009. Inferring population continuity versus replacement with aDNA: A cautionary tale from the Aleutian Islands. Hum. Biol. 81(4):19-38. 